\title{
To what extent does IQ 'explain' socio-economic variations in function?
}

\author{
Hans Bosma*1, Martin PJ van Boxtel², Gertrudis IJM Kempen², \\ Jacques ThM van Eijk ${ }^{1}$ and Jelle Jolles ${ }^{2}$
}

Address: ${ }^{1}$ Maastricht University, Social Medicine, PO Box 616, 6200 MD Maastricht, The Netherlands, ${ }^{2}$ Maastricht University, Psychiatry and Neuropsychology, PO Box 616, 6200 MD Maastricht, The Netherlands and ${ }^{3}$ Maastricht University, School for Public Health and Primary Care, P.O. Box 616, 6200 MD Maastricht, The Netherlands

Email: Hans Bosma* - hans.bosma@zw.unimaas.nl; Martin PJ van Boxtel - martin.vanboxtel@np.unimaas.nl; Gertrudis IJM Kempen - g.kempen@zw.unimaas.nl; Jacques ThM van Eijk - j.vaneijk@zw.unimaas.nl; Jelle Jolles - j.jolles@np.unimaas.nl

* Corresponding author

Published: 25 July 2007

BMC Public Health 2007, 7:179 doi:10.1 I86/147|-2458-7-179
Received: 18 December 2006

Accepted: 25 July 2007

This article is available from: http://www.biomedcentral.com/I47/-2458/7//79

(c) 2007 Bosma et al; licensee BioMed Central Ltd.

This is an Open Access article distributed under the terms of the Creative Commons Attribution License (http://creativecommons.org/licenses/by/2.0), which permits unrestricted use, distribution, and reproduction in any medium, provided the original work is properly cited.

\begin{abstract}
Background: The aims of this study were to examine the extent to which higher intellectual abilities protect higher socio-economic groups from functional decline and to examine whether the contribution of intellectual abilities is independent of childhood deprivation and low birth weight and other socio-economic and developmental factors in early life.
\end{abstract}

Methods: The Maastricht Aging Study (MAAS) is a prospective cohort study based upon participants in a registration network of general practices in The Netherlands. Information was available on I2II men and women, $24-81$ years old, who were without cognitive impairment at baseline (1993 - 1995), who ever had a paid job, and who participated in the six-year follow-up. Main outcomes were longitudinal decline in important components of quality of life and successful aging, i.e., self-reported physical, affective, and cognitive functioning.

Results: Persons with a low occupational level at baseline showed more functional decline than persons with a high occupational level. Socio-economic and developmental factors from early life hardly contributed to the adult socio-economic differences in functional decline. Intellectual abilities, however, took into account more than one third of the association between adult socioeconomic status and functional decline. The contribution of the intellectual abilities was independent of the early life factors.

Conclusion: Rather than developmental and socio-economic characteristics of early life, the findings substantiate the importance of intellectual abilities for functional decline and their contribution - as potential, but neglected confounders - to socio-economic differences in functioning, successful aging, and quality of life. The higher intellectual abilities in the higher socioeconomic status groups may also underlie the higher prevalences of mastery, self-efficacy and efficient coping styles in these groups. 


\section{Background}

Lately there have been reports that lower intellectual abilities may result in poor physical functioning and even in heightened risks of mortality [1-9]. The mechanisms underlying the association, however, remain undetermined. In particular, the issue of whether lower intellectual abilities are related to poor health outcomes, independent of adverse socio-economic conditions in childhood and adulthood, remains unresolved [5,10]. A related unresolved issue is whether the association between low socio-economic status and poor health is confounded by lower intellectual abilities in the lower socio-economic groups $[11,12]$. In this context, intelligence has even been postulated as the "elusive fundamental cause of social class inequalities in health" [13]. Given strong associations between intellectual abilities and where people end up in the socio-economic hierarchy [14], taking into account potential confounding by intellectual abilities perhaps should indeed have an increased priority in studies of socio-economic differences in health. A recent finding of the London-based Whitehall II study showed that intelligence probably is not the driving force behind socioeconomic inequalities in health in white-collar workers [15]. Another recent study, however, showed that controlling for intelligence led to a marked reduction in the magnitude of the socioeconomic gradients in health [16]. In both studies, health measures varied from self-reported mental and physical functioning to coronary heart disease and all-cause mortality.

Using longitudinal data from the Maastricht Aging Study (MAAS), the present study further examines whether the higher intellectual abilities in the high socio-economic status groups protect these groups from declines in reports of physical, affective and cognitive functioning. It is of relevance to study individual perceptions of physical, affective, and cognitive functioning, because these have been identified as valid indicators of quality of life [17] and successful aging [18]. The person-centered (rather than doctor-centered) perspective is increasingly acknowledged an equivalent outcome measure. Increasingly, these measures are also used in clinical trials, as the personal experience might be more decisive for using health care services than many so-called "objective" measures [17]. Given that intellectual abilities may have been negatively influenced by adverse socioeconomic conditions in childhood (e.g. deprivation) [19] or adverse developmental factors (e.g. low birth weight, childhood disease) [20], these characteristics were taken into account. Figure 1 further clarifies the underlying research model.

\section{Methods}

\section{Study population}

MAAS started as a prospective study of the determinants of normal cognitive aging [21,22]. Participants in MAAS were recruited from a registration network of general practices in the South of The Netherlands. Twenty-four to eighty-one year old men and women were considered eligible. Individuals were excluded if they had a history of stroke, mental retardation, or chronic neurological pathology (e.g. dementia, epilepsy, Parkinson, or central nervous system malignancy). Participants were stratified by age (12 groups), sex, and occupational achievement (two groups). At baseline (1993 - 1995), 1821 individuals were medically and neuropsychologically tested at the University laboratory. A questionnaire had to be filled out at home. Six years later (1999 - 2001), 1376 (75.6\%) individuals returned for follow-up assessment. A group of $271(14.9 \%)$ individuals refused further participation, 118 (6.3\%) had died, 37 (2.0\%) were medically unfit to participate and $19(1.0 \%)$ did not take part for other reasons. MAAS was approved by the Medical Ethics Committee of the University Hospital Maastricht. All participants gave their written informed consent.

\section{Physical, affective, and cognitive functioning}

At both baseline and follow-up phase, physical functioning was determined by asking whether or not people due to their physical condition - needed help with the following activities (Instrumental Activities of Daily Living): shopping, household chores, preparation of meals, personal care, and getting dressed (internal consistency measure: Cronbach's $\alpha=0.72$ ). These items were summed. Affective functioning was determined by the depression subscale of the widely used Symptom Checklist [23]. There are 16 five-category items asking whether persons were hindered by depressive thoughts and feelings during the last week (Cronbach's $\alpha=0.89$ ). The items were summed. Cognitive functioning was determined by a question asking about bother due to forgetfulness in daily life (1: not at all - 5: very much). This information has been shown to be related to health care consumption for cognitive complaints and has been used as an indicator of cognitive capacity in several large-scale studies (e.g. [2426]). All three measures were subsequently rescaled into variables ranging from 0 (good function) to 100 (poor function).

\section{Adult socio-economic status}

Socio-economic status was defined by the respondents' occupational level using the International Socio-Economic Index of Occupational Status (ISEI) based upon job title codes, as used by Statistics Netherlands [27]. The resulting score was divided into thirds (using tertiles). There were 165 persons who never had any paid job.

\section{Intellectual abilities}

At baseline, intellectual abilities were measured with the abbreviated version of the Groningen Intelligence Test (GIT) [28]. The GIT is the most frequently used intelli- 


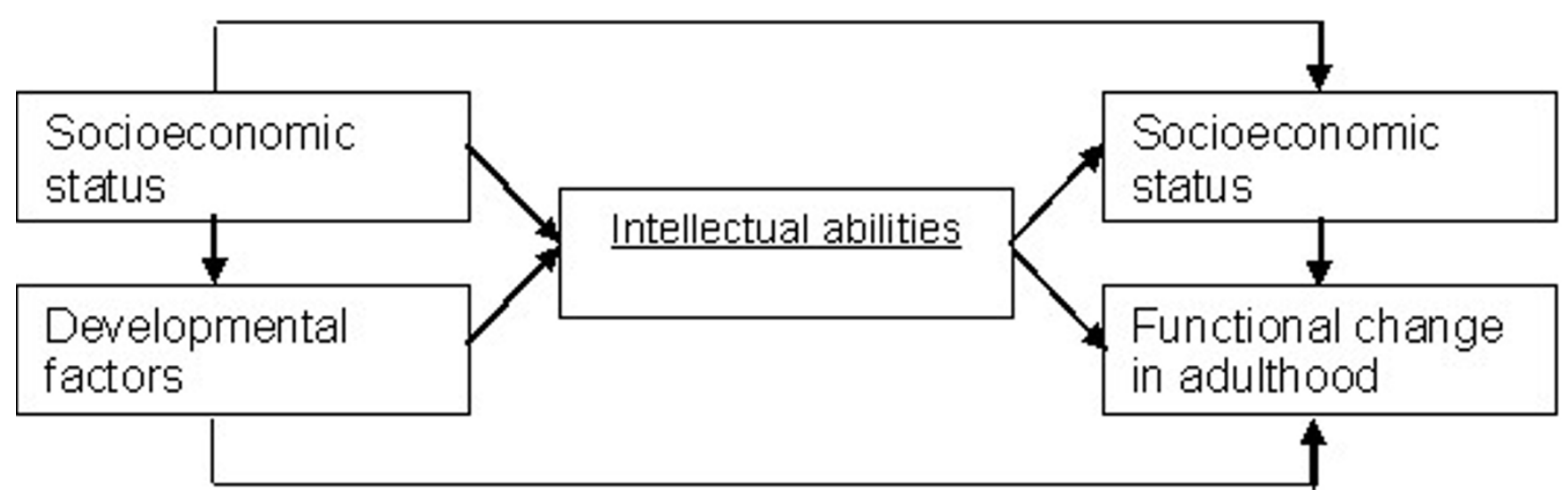

Figure I

The research model.

gence test of formal IQ in The Netherlands and, although analogous to the Wechsler Adult Intelligence Scale, relies less on the persons' verbal abilities. There are five subtests: analogies, fluency, doing sums, vocabulary, and mental rotation. The sub-tests correlations varied from 0.09 (between mental rotation and doing sums) to 0.54 (between mental rotation and analogies). One composite score reflecting the full scale intelligence level was created ( sample mean $=115.4 ;$ sd $=13.1)$.

\section{Early life socioeconomic conditions}

Socioeconomic conditions during early life were measured with the educational level of the father and mother (both seven categories), and the occupational level of the father (ISEI index) [27]. These variables were divided into thirds (using tertiles). Deprivation in childhood was measured with a question about whether, in childhood, there was frequently not enough money to buy basic goods (e.g. food, clothes).

\section{Early life developmental factors}

Early developmental factors were measured with retrospective reports about whether or not persons as a child or baby experienced an assisted birth, low birth weight (less than 2500 grams), nuchal cord (i.e. umbilical cord wrapped around baby's neck), or delayed developmental milestones (e.g. late start talking, walking). Severe diseases during childhood or adolescence were measured by asking whether or not respondents had to repeat classes at school due to severe illnesses.

\section{Statistical analysis}

Firstly, basic statistics (percentages and means) of all covariates are compared between occupational groups. Secondly, associations between socio-economic status and physical, affective, and cognitive functioning at baseline and at the follow-up phase and the six-year changes were analyzed with analysis of variance, controlling for age and sex (and for baseline functioning, when analyzing the association with changes in functioning). Thirdly, associations of early socioeconomic and developmental factors and intellectual abilities with six-year changes in physical, affective, and cognitive functioning were examined by linear regression analyses, controlling for age, sex, and baseline functioning. Fourthly, the association between adult occupational level and changes in functioning was analyzed with linear regression analyses. Three models were estimated and compared: model 1 was adjusted for age, sex, and baseline functioning; model 2 was additionally adjusted for early socioeconomic and developmental factors; and model 3 was additionally adjusted for intellectual abilities. This hierarchy of models quantifies the contribution of intellectual abilities (to the socio-economic differences in function), net of (i.e. corrected for) the potentially confounding influence of developmental and socioeconomic factors from childhood. The percent decrease of the unstandardised regression coefficients for occupational level, when including new variables, indicates the extent to which the new variables 'explain' the socioeconomic effects. To increase power, these latter analyses were also done with the continuous measures of both occupational level and intellectual abilities. Assumptions of linear regression were checked and found to be not violated.

\section{Results}

Table 1 shows that there were fewer women in the higher occupational groups (35 versus $42 \%$ in the lower occupational groups). Intellectual abilities were also lower in these groups; only 10 percent had lower intellectual abilities compared with 49 percent in the lower occupational groups. Current occupational level was also strongly related to the socioeconomic conditions in childhood. Of the early developmental factors (all with rather low prev- 
alences), only delayed milestones was significantly less common in the higher occupational groups.

There was no association between adult occupational level and physical, affective, and cognitive functioning at baseline (Table 2). Except for men and women with a high occupational level who experienced positive changes in their cognitive functioning (-0.91), all groups showed declines in all three types of functioning (reflected in the positive change scores). The strongest declines occurred in the lowest socioeconomic group. Given the theoretical range of the functioning measures (from 0: good to 100: poor), average scores, longitudinal declines, and socioeconomic differences therein were small.

Intellectual abilities were lower in persons with poor socioeconomic conditions during childhood or adulthood (not tabulated). Those with reports of severe diseases in childhood also had lower intellectual abilities. Other developmental factors were not related to the intellectual abilities.

Table 3 shows that early socioeconomic conditions were not consistently related to the three different measures of functional decline. Childhood deprivation, father's low educational level, and father's occupational level were significantly related to adverse physical, affective, and cognitive changes, respectively. The coefficient of 3.94 indicates that reports of childhood deprivation were related to 3.94 points more six-year decline in physical functioning compared with better-off counterparts. Early developmental factors were not related to functional decline, except for a strong adverse effect of delayed milestones on declining physical function (b coefficient: 4.90). Low intellectual abilities, on the other hand, were strongly related to declines across all three types of functional change.

Compared with persons with a high occupational level, persons with a low occupational level declined 2.43, 2.81 and 3.96 points more during the six-year follow-up compared with persons with a high occupational level (Table 4). An early socioeconomic indicator was created by counting the number of times persons were in the poorest category across the four early socioeconomic variables. An early developmental indicator was similarly created from the developmental items. When introduced in model 2, the coefficients for socioeconomic status did not change substantially. The socioeconomic coefficients for changes in affective functioning decreased with 19 and $11 \%$, respectively, indicating that a small part of the socioeconomic differences in affective functioning may be based on early life factors. When the intellectual abilities were (additionally) introduced in model 3, the coefficients of socioeconomic status decreased substantially. More than one third of the association between adult occupational level and longitudinal changes in physical, affective, and cognitive functioning was taken into account by the lower intellectual abilities in the lower occupational groups. In the latter model, none of the coefficients related to socioeconomic status remained statistically significant.

Findings were even more pronounced when the continuous measures of both occupational level and intellectual abilities were used (Table 4). On average, early life factors hardly contributed to the socioeconomic differences in functional decline, while intellectual abilities even had a higher contribution. Of the socioeconomic differences in physical, affective, and cognitive decline, 57, 50, and 33

Table I: Characteristics of the study population by occupational level

\begin{tabular}{|c|c|c|c|c|}
\hline & \multicolumn{4}{|c|}{ Occupational level: } \\
\hline & $\begin{array}{c}\text { Total } \\
(n=|2| 1)\end{array}$ & $\begin{array}{c}\text { High } \\
(n=385)\end{array}$ & $\begin{array}{l}\text { Intermediate } \\
(n=422)\end{array}$ & $\begin{array}{c}\text { Low } \\
(n=404)\end{array}$ \\
\hline Women (\%) & 48.6 & 34.5 & 57.3 & $41.8 *$ \\
\hline Age, mean (SD) & $50.3(15.4)$ & $50.2(14.7)$ & $48.5(15.3)$ & $50.1(15.1)$ \\
\hline Low intellectual abilities (\%) & 31.6 & 10.4 & 27.7 & $48.8 *$ \\
\hline \multicolumn{5}{|l|}{ Early socioeconomic conditions } \\
\hline Deprivation (\%) & 7.0 & 4.8 & 5.7 & $12.7 *$ \\
\hline Low occupational level of father (\%) & 36.0 & 26.6 & 33.4 & $47.0 *$ \\
\hline Low educational level of father (\%) & 54.9 & 44.7 & 53.7 & $63.5 *$ \\
\hline Low educational level of mother (\%) & 65.5 & 59.0 & 60.3 & $73.9 *$ \\
\hline \multicolumn{5}{|l|}{ Early developmental factors } \\
\hline Assisted birth (\%) & 5.0 & 5.8 & 3.9 & 5.6 \\
\hline Low birth weight (\%) & 4.4 & 3.0 & 5.2 & 5.4 \\
\hline Nuchal cord $(\%)$ & 2.4 & 2.3 & 1.9 & 3.4 \\
\hline Delayed milestones (\%) & 4.6 & 2.4 & 6.5 & $4.3 *$ \\
\hline Severe disease in childhood (\%) & 7.2 & 4.9 & 7.6 & 9.2 \\
\hline
\end{tabular}

$* p<.05$ 
Table 2: Mean physical, affective, and cognitive functioning at baseline and six-year follow-up phase, according to adult occupational level, adjusted for age and sex (analysis of variance); mean six-year functional change score is additionally adjusted for baseline functioning (analysis of variance) $(N=1211)^{a}$

\begin{tabular}{|c|c|c|c|}
\hline & \multicolumn{3}{|c|}{ Mean functioning: } \\
\hline & At baseline & At follow-up & Six-year change \\
\hline \multicolumn{4}{|l|}{ Physical functioning } \\
\hline High occupational level & 2.97 & 4.35 & 1.87 \\
\hline Intermediate level & 2.05 & 4.24 & 2.31 \\
\hline Low occupational level & 2.30 & $6.76 *$ & $4.29 *$ \\
\hline \multicolumn{4}{|l|}{ Affective functioning } \\
\hline High occupational level & 6.83 & 15.95 & 9.12 \\
\hline Intermediate level & 6.75 & 16.56 & 9.85 \\
\hline Low occupational level & 6.93 & $18.79 *$ & $11.94 *$ \\
\hline \multicolumn{4}{|l|}{ Cognitive functioning } \\
\hline High occupational level & 17.39 & 16.40 & -0.91 \\
\hline Intermediate level & 15.73 & 16.83 & 0.46 \\
\hline Low occupational level & 18.35 & $20.53 *$ & $3.05 *$ \\
\hline
\end{tabular}

$* p<.05$.

a Measures for functioning range from 0 (good) to 100 (poor); change score indicates follow-up minus baseline score. Positive values for the change score indicate longitudinal decline; negative values indicate improvement.

percent, respectively, were taken into account by intellectual abilities.

Table 5 presents the findings for the five sub-tests of the GIT intelligence test. It shows that the vocabulary sub-test took into account most of the effect of occupational level. At least 37 percent of the adverse effect of low adult occupational level on functional decline was taken into account by lower vocabulary scores in lower occupational groups. The highest contribution of the vocabulary subtest holds across all three domains of functional decline. The effect of occupational level was not significant in any model with vocabulary scores included (not tabulated).

Intellectual abilities had similar effects in low and high socio-economic status groups and in the young and old (not tabulated). The contribution of the intellectual abilities to the socio-economic differences in functioning was somewhat stronger in men than in women. Furthermore, associations were similar using educational and income level as indicators of socioeconomic status (not tabulated). The associations with income level were somewhat weaker though, perhaps because income was only measured at the follow-up phase. The analyses with the alternative socioeconomic measures included the 165 persons who never had any paid job and who were thus excluded in the analyses with occupational level. In contrast to the occupational level indicator though, educational and income level were also related to baseline affective and cognitive functioning.

\section{Discussion}

Lower intellectual abilities in the lower socio-economic status groups took into account more than one third of the reported socio-economic differences in the decline in important components of quality of life and successful aging, i.e physical, affective, and cognitive functioning. None of the socioeconomic differences in functional decline remained statistically significant, when intellectual abilities were included in the model. The contribution of intellectual abilities was independent of the potentially confounding influence of early life socioeconomic conditions, including childhood deprivation, and early life developmental factors, including low birth weight. This was particularly due to only small effects of these early conditions on later functional decline.

A major drawback of our study is that the intellectual abilities were measured at baseline, when the respondents were 25 years old or older. We cannot exclude the possibility that intellectual abilities have changed as a result of socioeconomic circumstances and related work characteristics (rather than vice versa). The vocabulary sub-test of the GIT contributed most strongly to the association between socio-economic status and longitudinal decline in functioning. This is relevant here, as such crystallized abilities are thought to be particularly sensitive to educational experiences [29]. But, also if intellectual abilities can be stimulated by socioeconomic circumstances, such as being in an active job [30] or having a high education, our findings emphasize the importance of intellectual 
Table 3: Regression coefficients (b) for socioeconomic and developmental conditions during childhood and intellectual abilities predicting six-year change in physical, affective, and cognitive functioning in adulthood, adjusted for age, sex, and baseline level of functioning $(N=|2| I)^{a}$

\begin{tabular}{|c|c|c|c|c|c|c|c|}
\hline \multicolumn{8}{|c|}{ Six-year change in: } \\
\hline & & \multicolumn{2}{|c|}{ Physical functioning } & \multicolumn{2}{|c|}{ Affective functioning } & \multicolumn{2}{|c|}{ Cognitive functioning } \\
\hline & & B & $95 \% \mathrm{Cl}$ & B & $95 \% \mathrm{Cl}$ & B & $95 \% \mathrm{Cl}$ \\
\hline \multicolumn{8}{|l|}{ Early socioeconomic conditions } \\
\hline \multirow[t]{2}{*}{ Deprivation } & No & 0 & (reference) & 0 & (reference) & 0 & (reference) \\
\hline & Yes & 3.94 & $(1.26,6.61)$ & 1.66 & $(-1.44,4.77)$ & -0.09 & $(-3.89,3.7 I)$ \\
\hline \multirow[t]{3}{*}{ Occupational level of father } & High & 0 & (reference) & 0 & (reference) & 0 & (reference) \\
\hline & Intermediate & -0.15 & $(-1.96,1.65)$ & 0.85 & $(-1.24,2.95)$ & 2.51 & $(0.02,5.01)$ \\
\hline & Low & -0.08 & $(-1.78,1.61)$ & 1.54 & $(-0.4 I, 3.50)$ & 3.72 & $(1.40,6.05)$ \\
\hline \multirow[t]{3}{*}{ Educational level of father } & High & 0 & (reference) & 0 & (reference) & 0 & (reference) \\
\hline & Intermediate & -0.42 & $(-2.48,1.65)$ & 3.29 & $(0.75,5.82)$ & 2.57 & $(-0.52,5.67)$ \\
\hline & Low & 0.27 & $(-1.51,2.04)$ & 2.86 & $(0.70,5.02)$ & 2.96 & $(0.32,5.60)$ \\
\hline \multirow[t]{3}{*}{ Educational level of mother } & High & 0 & (reference) & 0 & (reference) & 0 & (reference) \\
\hline & Intermediate & 0.44 & $(-1.94,2.82)$ & -0.22 & $(-3.09,2.65)$ & 1.15 & $(-2.36,4.65)$ \\
\hline & Low & -0.36 & $(-2.46,1.75)$ & 0.91 & $(-1.63,3.44)$ & 0.61 & $(-2.47,3.70)$ \\
\hline \multicolumn{8}{|l|}{ Early developmental factors } \\
\hline \multirow{2}{*}{ Assisted birth } & No & 0 & (reference) & 0 & (reference) & 0 & (reference) \\
\hline & Yes & 0.68 & $(-2.75,4.11)$ & -1.77 & $(-5.54,2.00)$ & 0.03 & $(-4.7 I, 4.76)$ \\
\hline \multirow[t]{2}{*}{ Low birth weight } & No & 0 & (reference) & 0 & (reference) & 0 & (reference) \\
\hline & Yes & 1.24 & $(-2.03,4.5 I)$ & -0.47 & $(-4.47,3.53)$ & -1.04 & $(-5.86,3.77)$ \\
\hline \multirow[t]{2}{*}{ Nuchal cord } & No & 0 & (reference) & 0 & (reference) & 0 & (reference) \\
\hline & Yes & -0.09 & $(-4.46,4.27)$ & 1.57 & $(-3.83,6.98)$ & 0.53 & $(-0.72,1.78)$ \\
\hline \multirow[t]{2}{*}{ Delayed milestones } & No & 0 & (reference) & 0 & (reference) & 0 & (reference) \\
\hline & Yes & 4.90 & $(1.65,8.14)$ & 0.07 & $(-3.94,4.07)$ & 0.68 & $(-4.35,5.7 I)$ \\
\hline \multirow[t]{2}{*}{ Severe disease in childhood } & No & 0 & (reference) & 0 & (reference) & 0 & (reference) \\
\hline & Yes & 0.16 & $(-2.47,2.79)$ & 1.41 & $(-1.63,4.45)$ & 1.27 & $(-2.39,4.94)$ \\
\hline \multirow[t]{3}{*}{ Intellectual abilities } & High & 0 & (reference) & 0 & (reference) & 0 & (reference) \\
\hline & Intermediate & 1.83 & $((0.14,3.52)$ & 0.44 & $(-1.51,2.38)$ & -0.33 & $(-2.68,2.02)$ \\
\hline & Low & 2.92 & $(1.16,4.69)$ & 2.37 & $(0.33,4.4 I)$ & 4.60 & $(2.14,7.06)$ \\
\hline
\end{tabular}

a Reference category is 'high' for occupational level of the father, educational level of the parents, and intellectual abilities. Reference category is 'no' for all other variables.

abilities for socioeconomic differences in health and functioning. The study of Batty and colleagues also reported substantial "explanation" by differences in intelligence [16]. Recent Whitehall II findings, on the contrary, indicated that intellectual abilities are probably not the driving force behind socioeconomic differences in health [15]. It is unclear how to explain this contrast among findings, but differences in the study population's composition, research design, age range, and measures of socioeconomic grading, health status, and intellectual abilities may be important. Foremost, our findings indicate that low socio-economic status cannot be established as a risk factor or indicator for functional decline, poor quality of life, and unsuccessful aging, until the possibility of confounding by intellectual abilities is fully excluded $[11,13]$.

Our findings thus show that intelligence is also informative for future deterioration of experienced quality of life. The personal functional experience and its "objective" counterparts, such as physical, performance-based tests or cognitive, neuropsychological tests are not necessarily perfectly related [31]. Equally well, there is no perfect relation between the reported functional decline and disease [31]. As mentioned previously, however, such quality of life measures are important for their patient-centeredness and their relevance for use of health care services $[17,18]$. Moreover, the findings may shed some further light on the complexity of the mechanisms linking intelligence and premature mortality (as reported by others, e.g. [16]). As we will discuss below, personal perceptions of coping and mastery - related to functional outcomes - may be important here (see also [32]). As there were only few incident cases of coronary heart disease and all-cause mortality, these outcomes must await examination after longer follow-up intervals. In our data, prevalent disease appeared not to contribute to socioeconomic differences in functioning (see below) [33]. In previous studies, however, findings were about similar across health measures, including (coronary heart disease) mortality and self- 
Table 4: Regression coefficients (b) for adult occupational level predicting six-year change in physical, affective, and cognitive functioning in adulthood. adjusted for age, sex, and baseline level of functioning (Model I), additionally adjusted for childhood socioeconomic conditions and developmental factors in early life (Model 2), and additionally adjusted for intellectual abilities (Model 3) $(N=1211)^{a}$

\begin{tabular}{|c|c|c|c|c|c|c|c|c|}
\hline & Model I & & Model 2 & & & Model 3 & & \\
\hline & B & $95 \% \mathrm{Cl}$ & B & $95 \% \mathrm{Cl}$ & & B & $95 \% \mathrm{Cl}$ & \\
\hline \multicolumn{9}{|l|}{ Physical functioning } \\
\hline High occupational level & 0.00 & (reference) & 0.00 & (reference) & & 0.00 & (reference) & \\
\hline Intermediate level & 0.44 & $(-1.29,2.17)$ & 0.41 & $(-1.33,2.15)$ & [07] & -0.12 & $(-1.88,1.63)$ & {$[>100]$} \\
\hline Low occupational level & 2.43 & $(0.70,4.15)$ & 2.44 & $(0.68,4.20)$ & {$[00]$} & 1.02 & $(-0.89,2.94)$ & {$[58]$} \\
\hline Continuous measures $^{b}$ & 0.07 & $(0.02,0.12)$ & 0.07 & $(0.02,0.12)$ & {$[00]$} & 0.03 & $(-0.03,0.08)$ & [57] \\
\hline \multicolumn{9}{|l|}{ Affective functioning } \\
\hline High occupational level & 0.00 & (reference) & 0.00 & (reference) & & 0.00 & (reference) & \\
\hline Intermediate level & 0.73 & $(-1.32,2.78)$ & 0.59 & $(-1.47,2.65)$ & {$[19]$} & 0.26 & $(-1.83,2.36)$ & {$[56]$} \\
\hline Low occupational level & 2.81 & $(0.77,4.86)$ & 2.49 & $(0.40,4.58)$ & {$[11]$} & 1.73 & $(-0.56,4.01)$ & {$[31]$} \\
\hline Continuous measures & 0.08 & $(0.02,0.13)$ & 0.07 & $(0.01,0.12)$ & [13] & 0.04 & $(-0.02,0.11)$ & [50] \\
\hline \multicolumn{9}{|l|}{ Cognitive functioning } \\
\hline High occupational level & 0.00 & (reference) & 0.00 & (reference) & & 0.00 & (reference) & \\
\hline Intermediate level & 1.37 & $(-1.13,3.86)$ & 1.31 & $(-1.20,3.81)$ & [04] & 0.70 & $(-1.85,3.24)$ & [47] \\
\hline Low occupational level & 3.96 & $(1.47,6.44)$ & 3.84 & $(1.30,6.38)$ & [03] & 2.44 & $(-0.33,5.22)$ & [37] \\
\hline Continuous measures & 0.12 & $(0.05,0.19)$ & 0.12 & $(0.05,0.19)$ & [00] & 0.08 & $(0.00,0.16)$ & [33] \\
\hline
\end{tabular}

a Between brackets is the percentage decline of the B-coefficient compared with the previous model. It indicates the extent to which newly introduced variables 'explain' the association of adult occupational level with physical, affective, and cognitive functioning. ${ }^{b}$ Analyses done using continuous measures of both intellectual abilities and occupational level (post-recode range: -87 (high) to - 16 (low)).

reports of physical and mental functioning $[15,16]$. However, the IQ contribution was somewhat stronger for the mortality outcomes in Batty and colleagues' study [16].

Lower intellectual abilities might affect rates of decline in functioning through adverse health behaviours [9,34-37]. Unawareness of the consequences of unhealthy behaviours, such as smoking or a sedentary lifestyle, may be a mediating pathway. A related mediating pathway in the association between intellectual abilities and functioning might be via somatic diseases $[4,6,8]$. Perhaps persons with lower abilities have higher prevalences of disease (via their unhealthy behaviours might be one route). However, we have shown that prevalent adult diseases and health behaviours (and life-events) hardly contributed to the socioeconomic differences in physical, affective, and cognitive functioning and thus that intellectual abilities were probably not related to declines in functioning through behavioural or disease-related pathways [33]. Although the present study is not about mechanisms underlying the association between intellectual abilities and declines in functioning in varying domains, it is striking to find in our data a positive association between intellectual abilities and a measure of control beliefs (mastery) (these beliefs were measured at the follow-up phase only). The Pearson correlation was $0.26(\mathrm{p}=0.05)$ (not tabulated). This suggests that higher intellectual abilities may help people to cope more easily with daily hassles, life events, and chronic stressful circumstances. Batty and Deary also postulated the possibility of a route via stress management skills as one of the mechanisms through which intelligence affects health [34]. Intelligence is about effectively dealing with complexity. Effective experiences, particularly in adverse and complex circumstances, are likely to increase levels of mastery and self-efficacy. Having to adhere to complex treatment regimens may be one such stressful circumstance with which the higher classes - because of their higher intellectual abilities - cope more effectively $[6,11,34]$.

\section{Further methodological considerations}

Some further methodological issues should be discussed. Firstly, the psychometric quality of the outcome measures could be questioned. The physical functioning items showed a moderate to high internal consistency (Cronbach's $\alpha=0.72$ ) and strongly resemble items in wellknown scales of instrumental activities of daily living [38]. The affective functioning items, though restricted to depression, come from a depression scale that has a high reliability and validity (Cronbach's $\alpha$ in our study $=0.89$ ) [23]. The cognitive function item asks for bother due to forgetfulness. Such complaint is not necessarily strongly related to test performance. A recent study, however, found that persons with cognitive complaints (but normal test performance) showed brain atrophy similar to that of amnestic mild cognitive impairment [39]. Another recent study found that perceived memory function was a predictor of subsequent memory performance [40]. Other research confirms the importance of self-reports [24$26,41]$. Important here is also that intelligence is related 
Table 5: Percentage of the effect of low and intermediate level adult occupation (compared with high occupational level) taken into account by sub-tests of the Groningen Intelligence Test a

\begin{tabular}{|c|c|c|c|c|c|}
\hline & \multicolumn{5}{|c|}{$\%$ taken into account by: } \\
\hline & Doing Sums & Vocabulary & Mental Rotation & Analogies & Fluency \\
\hline \multicolumn{6}{|l|}{ Physical functioning } \\
\hline High occupational level & (reference) & (reference) & (reference) & (reference) & (reference) \\
\hline Intermediate level & $49 \%$ & $>100 \%$ & $22 \%$ & $100 \%$ & $34 \%$ \\
\hline Low occupational level & $44 \%$ & $64 \%$ & $07 \%$ & $34 \%$ & $14 \%$ \\
\hline \multicolumn{6}{|l|}{ Affective functioning } \\
\hline High occupational level & (reference) & (reference) & (reference) & (reference) & (reference) \\
\hline Intermediate level & $09 \%$ & $59 \%$ & $34 \%$ & $66 \%$ & $00 \%$ \\
\hline Low occupational level & $15 \%$ & $37 \%$ & $12 \%$ & $28 \%$ & $00 \%$ \\
\hline \multicolumn{6}{|l|}{ Cognitive functioning } \\
\hline High occupational level & (reference) & (reference) & (reference) & (reference) & (reference) \\
\hline Intermediate level & $21 \%$ & $45 \%$ & $05 \%$ & $30 \%$ & $24 \%$ \\
\hline Low occupational level & $23 \%$ & $37 \%$ & $02 \%$ & $16 \%$ & $18 \%$ \\
\hline
\end{tabular}

a The percentage is the percentage decline of the B-coefficients of the effect of adult occupational level in the model with the particular intelligence sub-test included compared with the model without that sub-test (i.e. model 2 in Table 3).

to changes in the reported functioning (controlling for the baseline score) which indicates that reporting bias (e.g. negative affectivity) is less likely; negative affectivity would similarly bias reports of both baseline and followup reports of functioning and its bias is avoided when analyzing change.

Secondly, not many experienced major declines in functioning and most started from high levels of functioning. Residuals in the linear regression were, however, normally distributed, and findings were similar in old persons where there is more poor function and longitudinal decline. The high mean level of intellectual abilities (mean $=115.4 ; \mathrm{SD}=13.1)$ may also be indicative of the initially well-functioning MAAS cohort. Thirdly, persons with a low socioeconomic status, as well as persons with poor functioning and persons with low intellectual abilities more often dropped out during the study (particularly due to refusal rather than death or any other cause of attrition) [42]. This pattern of attrition may underlie the small six-year functional decline (from a high level of functioning) and the small socio-economic status and intelligencerelated differences therein. It cannot, however, be determined how this pattern might have affected our finding of a substantial contribution of intellectual abilities. Fourthly, persons with a mental retardation were excluded from MAAS at baseline. Furthermore, excluding outliers and influential cases did not result in different findings. Hence, findings are probably not based on few persons with extreme low scores on the intellectual abilities measure.

Fifthly, birth weight and complications during birth and other developmental factors were based on self-reports and may therefore have been subject to recall bias, espe- cially in older persons $[43,44]$. However, the analysis of functional decline rather than momentary function excluded the possibility that overreports of adversities in childhood by those with poor functional outcomes could cause overestimated associations between childhood factors and our functional outcome. The extent of non-differential reporting bias is still unclear, as is the extent to which this might underlie the absence of effects of these factors on decline in adulthood.

Sixthly, if our measure of intellectual abilities also picks up characteristics, such as verbal abilities and differences in being used to test-taking, higher occupational level groups might have (artificially) higher scores on the particular measure. More research is needed to examine this issue in more detail [45]. Seventhly, the educational level of the parents might be a surrogate measure of the parents' intellectual ability levels, through which any effect of the parents' education might actually be confounded. In the absence of a consistent effect of the parents' education, such confounding has not likely played a major role. Finally, findings should be interpreted cautiously, because it is unclear why education and income, but not occupation, were related to affective and cognitive function at baseline.

\section{Conclusion}

Rather than developmental (e.g. birth weight) and socioeconomic (e.g. deprivation) characteristics of early life, our findings substantiate the importance of intellectual abilities for physical, affective, and cognitive decline and their contribution - as potential, but neglected confounders - to socio-economic differences in functioning, successful aging, and quality of life. The higher intellectual abilities in the higher socio-economic status groups may 
also underlie the higher prevalences of mastery, self-efficacy and efficient coping styles in these groups.

\section{Competing interests}

The author(s) declare that they have no competing interests.

\section{Authors' contributions}

HB formulated the research questions, analysed the data, and wrote the paper. MPJvB and JJ coordinated data collection, contributed to the interpretation of the data and critically read the manuscript. GIJMK and JThMvE contributed to the interpretation of the data and critically read the manuscript. All authors approved the final manuscript.

\section{Acknowledgements}

This work was supported in part by a grant from the Dutch Ministries of Education and Health and Welfare via the Steering Committee for Gerontological Research (NESTOR).

We thank C Karimoen, M Kessel, R Landeweerd, A Quist, and N Rozendaal for assistance in medical and neuropsychological testing and constructing the database. The study was conducted in close collaboration with the Registration Network Family Practices, Maastricht University, and related general practitioners.

\section{References}

I. Bain GH, Lemmon H, Teunisse S, Starr JM, Fox HC, Deary IJ, Whalley LJ: Quality of Life in healthy old age: relationships with childhood IQ, minor psychological symptoms and optimism. Soc Psychiat Psychiat Epidemiol 2003, 38:632-636.

2. Deary IJ, Whiteman MC, Starr JM, Whalley LJ, Fox HC: The impact of childhood intelligence on later life: following up the Scottish mental surveys of 1932 and 1947. J Personal Soc Psychol 2004, 86: $130-\mid 47$

3. Gunnell D, Magnusson PK, Rasmussen F: Low intelligence test scores in 18 year old men and risk of suicide: cohort study. Brit Med J 2005, 330: 167-I7I.

4. Hart CL, Taylor MD, Davey Smith G, Whalley LJ, Starr JM, Hole DJ, Wilson V, Deary IJ: Childhood IQ, social class, deprivation, and their relationships with mortality and morbidity risk in later life: prospective observational study linking the Scottish Mental Survey 1932 and the Midspan studies. Psychosom Med 2003, 65:877-883.

5. Kuh D, Richards M, Hardy R, Butterworth S, Wadsworth ME: Childhood cognitive ability and deaths up until middle age: a postwar birth cohort study. Int J Epidemiol 2004, 33:408-4I3.

6. Martin LT, Fitzmaurice GM, Kindlon DJ, Buka SL: Cognitive performance in childhood and early adult illness: a prospective cohort study. J Epidemiol Community Health 2004, 58:674-679.

7. Osler M, Andersen AM, Due P, Lund R, Damsgaard MT, Holstein BE: Socioeconomic position in early life, birth weight, childhood cognitive function, and adult mortality. A longitudinal study of Danish men born in 1953. J Epidemiol Community Health 2003, 57:68I-686

8. Starr JM, Deary IJ, Lemmon H, Whalley LJ: Mental ability age I I years and health status age $\mathbf{7 7}$ years. Age Ageing 2000 29:523-528.

9. Whalley LJ, Deary IJ: Longitudinal cohort study of childhood IQ and survival up to age 76. Brit Med J 200I, 322:819.

10. Osler M, Batty GD: Commentary: influence of early life intelligence test performance on later health: do lower scoring children become less healthy adults? Int J Epidemiol 2004, 33:4|4-4I5.
II. Gottfredson LS: Intelligence: is it the epidemiologists' elusive "fundamental cause" of social class inequalities in health? J Personal Soc Psychol 2004, 86: I74-199.

12. Marmot M, Ryff CD, Bumpass LL, Shipley M, Marks NF: Social inequalities in health: next questions and converging evidence. Soc Sci Med 1997, 44:901-910.

13. Gottfredson LS, Deary IJ: Intelligence Predicts Health and Longevity, but Why? Cur Dir Psychol Sci 2004, I 3: I-4.

14. Bond R, Saunders P: Routes of success: influences on the occupational attainment of young British males. Brit J Sociol 1999 , 50:217-249.

15. Singh-Manoux A, Ferrie JE, Lynch JW, Marmot M: The role of cognitive ability (intelligence) in explaining the association between socioeconomic position and health: evidence from the Whitehall II prospective cohort study. Am J Epidemiol 2005, | 61:83 I-839.

16. Batty GD, Der G, Macintyre S, Deary IJ: Does IQ explain socioeconomic inequalities in health? Evidence from a population based cohort study in the west of Scotland. British Medical Journal 2006, 332:580-584.

17. Garratt A, Schmidt L, Mackintosh A, Fitzpatrick R: Quality of life measurement: bibliographic study of patient assessed health outcome measures. Brit Med | 2002, 324:|4|7-|42|.

18. Rowe JW, Kahn RL: Successful aging. Gerontologist 1997, 37:433-440.

19. Najman JM, Aird R, Bor W, O'Callaghan M, Williams GM, Shuttlewood GJ: The generational transmission of socioeconomic inequalities in child cognitive development and emotional health. Soc Sci Med 2004, 58: I | 47- I I 58

20. Shenkin SD, Starr JM, Deary IJ: Birth weight and cognitive ability in childhood: a systematic review. Psychol Bull 2004, 130:989-1013.

21. Jolles J, Houx PJ, Van Boxtel MPJ, Ponds RWHM: Maastricht Aging Study; Determinants of cognitive aging Maastricht: Neuropsych Publishers; 1994.

22. Van Boxtel MPJ, Buntinx F, Houx PJ, Metsemakers JF, Knottnerus A Jolles J: The relation between morbidity and cognitive performance in a normal aging population. J Gerontol: Med Sci 1998 , 53:MI47-MI54

23. Derogatis LR, Rickels K, Rock AF: The SCL-90 and the MMPI: a step in the validation of a new self-report scale. Brit J Psychiat 1976, I 28:280-289.

24. Bassett SS, Folstein MF: Memory complaint, memory performance, and psychiatric diagnosis: A community study. J Geriat Psychiat Neurol 1993, 6(2): I05-III.

25. Geerlings MI, Jonker C, Bouter LM, Ader HJ, Schmand B: Association between memory complaints and incident alzheimer's disease in elderly people with normal baseline cognition. Am J Psychiat 1999, 156:531-537.

26. Schofield PW, Marder K, Dooneief G, Jacobs DM, Sano M, Stern Y: Association of subjective memory complaints with subsequent cognitive decline in community-dwelling elderly individuals with baseline cognitive impairment. American Journal of Psychiatry 1997, I 54:609-6I5

27. Ganzeboom HBG, De Graaf PM, Treiman DJ: A Standard International Socio-Economic Index of Occupational Status. Soc Sci Res 1992, 2 I: I-56.

28. Luteijn F, Van der Ploeg FAE: Groninger Intelligentie Test: Handleiding [Groninger Intelligence Test: Manual] Lisse: Swets \& Zeitlinger; 1983.

29. Cattell RB: The theory of fluid and crystallized intelligence checked at the 5-6 year-old level. Brit J Educ Psychol I967, 37(2):209-224.

30. Bosma H, Van Boxtel MP, Ponds RW, Houx PJ, Burdorf A, Jolles J: Mental work demands protect against cognitive impairment: MAAS prospective cohort study. Exp Aging Res 2003, 29:33-45.

31. Verbrugge LM, Jette AM: The disablement process. Soc Sci Med 1994, 38: I- |4.

32. Bosma H, Schrijvers C, Mackenbach JP: Socioeconomic inequalities in mortality and importance of perceived control: cohort study. Brit Med J 1999, 3 I9: |469-1470.

33. Bosma H, Van Boxtel M, Kempen G, Van Eijk J, Jolles J: Why are lower social classes more depressed and anxious? Findings from the Maastricht Aging Study (MAAS). Int J Behav Med 2004, I I:223. 
34. Batty GD, Deary I): Early life intelligence and adult health. Brit Med J 2004, 329:585-586.

35. Batty GD, Deary IJ, Macintyre S: Childhood IQ in relation to risk factors for premature mortality in middle-aged persons: the Aberdeen Children of the 1950s study. J Epidemiol Community Health 2007, 6 I:24I-247.

36. Chandola T, Deary IJ, Blane D, Batty GD: Childhood IQ in relation to obesity and weight gain in adult life: the National Child Development (1958) Study. Int J Obes (Lond) 2006, 30: I422-I 432.

37. Taylor MD, Hart CL, Davey Smith G, Starr JM, Hole DJ, Whalley LJ, Wilson V, Deary IJ: Childhood mental ability and smoking cessation in adulthood: prospective observational study linking the Scottish Mental Survey 1932 and the Midspan studies. J Epidemiol Community Health 2003, 57:464-465.

38. Lawton MP, Brody EM: Assessment of older people: self-maintaining -and Instrument Activities of Daily living. Gerontologist 1969, 9:179-186.

39. Saykin AJ, Wishart HA, Rabin LA, Santulli RB, Flashman LA, West JD, McHugh TL, Mamourian AC: Older adults with cognitive complaints show brain atrophy similar to that of amnestic $\mathrm{MCI}$. Neurol 2006, 67:834-842.

40. Valentijn SA, Hill RD, Van Hooren SA, Bosma H, Van Boxtel MP, Jolles J, Ponds RW: Memory self-efficacy predicts memory performance: results from a 6-year follow-up study. Psychol Aging 2006, 21:165-172.

41. Mol ME, van Boxtel MP, Willems D, Jolles J: Do subjective memory complaints predict cognitive dysfunction over time? A sixyear follow-up of the Maastricht Aging Study. Int J Geriatric Psychiat 2006, $21: 432-441$.

42. Van Beijsterveldt CE, van Boxtel MP, Bosma $H$, Houx PJ, Buntinx F, Jolles J: Predictors of attrition in a longitudinal cognitive aging study: the Maastricht Aging Study (MAAS). I Clin Epidemiol 2002, 55:216-223.

43. Kauhanen L, Lakka HM, Lynch JW, Kauhanen J: Social disadvantages in childhood and risk of all-cause death and cardiovascular disease in later life: a comparison of historical and retrospective childhood information. Int J Epidemiol 2006, 35:962-968.

44. Walton KA, Murray LJ, Gallagher AM, Cran GW, Savage MJ, Boreham C: Parental recall of birthweight: a good proxy for recorded birthweight? Eur J Epidemiol 2000, 16:793-796.

45. Sternberg RJ, Cognition: The holey grail of general intelligence. Science 2000, 289:399-40I.

\section{Pre-publication history}

The pre-publication history for this paper can be accessed here:

http://www.biomedcentral.com/1471-2458/7/179/pre

pub
Publish with Biomed Central and every scientist can read your work free of charge

"BioMed Central will be the most significant development for disseminating the results of biomedical research in our lifetime. "

Sir Paul Nurse, Cancer Research UK

Your research papers will be:

- available free of charge to the entire biomedical community

- peer reviewed and published immediately upon acceptance

- cited in PubMed and archived on PubMed Central

- yours - you keep the copyright

Submit your manuscript here:

http://www.biomedcentral.com/info/publishing_adv.asp
BioMedcentral 